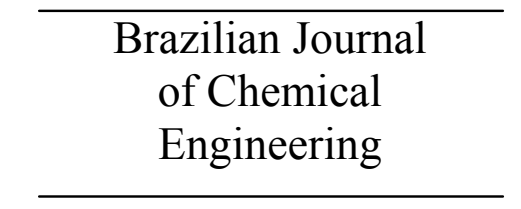

ISSN 0104-6632

Printed in Brazil

www.abeq.org.br/bjche

Vol. 26, No. 04, pp. 733 - 744, October - December, 2009

\title{
IN-LINE ESTIMATION OF SULFUR AND NITROGEN CONTENTS DURING HYDROTREATING OF MIDDLE DISTILLATES
}

\author{
M. E. Pacheco ${ }^{1}$, V. M. M. Salim² and J. C. Pinto ${ }^{2 *}$ \\ ${ }^{1}$ Petrobras/CENPES/PDAB/Plantas Piloto, Universidade Federal do Rio de Janeiro - RJ, Brasil. \\ ${ }^{2}$ Programa de Engenharia Química/COPPE, Universidade Federal do Rio de Janeiro - RJ, Brasil. \\ Programa de Engenharia Química/COPPE, Universidade Federal do Rio de Janeiro Cidade Universitária, \\ Phone: + (55) (21) 2562-8337, + (55) (21) 2562-8300, C.P. 68502, CEP: 21945-970, Rio de Janeiro - RJ, Brazil. \\ E-mail: pinto@peq.coppe.ufrj.br
}

(Submitted: January 24, 2009 ; Revised: April 4, 2009 ; Accepted: April 28, 2009)

\begin{abstract}
The main objective of this work is analyzing whether it is possible to develop an empirical correlation for in-line estimation of the sulfur and nitrogen contents of the middle distillates Hydrotreating (HDT) products for control purposes. Correlations are based only on readily available in-line information of specific gravity variation between feedstock and products, without considering any piece of information about the kinetic behavior of the catalyst. Experimental data were obtained in pilot plants under operating conditions that are representative of refinery operations. Results indicate that the removal of nitrogen and sulfur compounds during middle distillates HDT can be monitored in-line in real time, based on the available measurements of specific gravity. This allows for development and implementation of advanced in-line procedures for monitoring and control of the HDT process in real time.

Keywords: Hydrotreating; Middle distillates; Sulfur removal; Nitrogen removal; Specific gravity; In-Line monitoring.
\end{abstract}

\section{INTRODUCTION}

Hydroprocessing is a very important oil refining process. Its importance is even greater in Brazil, due to the characteristics of the Brazilian heavy oil, with high nitrogen and relatively low sulfur contents. Basically, hydrotreating (HDT) consists of treating oil fractions through hydrogen feeding, in the presence of catalysts, under specific conditions of temperature, pressure and residence time. HDT allows for improvement of the oil quality and reduction of the environmental impact of the final oil application, through reduction of the nitrogen and sulfur emissions. As a consequence, HDT leads to an increase of the processing capacity of heavy oil fractions, as heavy oil fractions are transformed into products of higher market value (Gates, 1979).
HDT reactions are intended to improve the properties of the processed feed and make the final properties meet very strict specifications, through removal of heteroatoms during hydrodesulfurization (HDS), hydrodenitrogenation (HDN) and hydrodemetalation reactions, and reduction of the aromatic and olefin contents through hydrogenation (Topsoe et al., 1996). HDT can also be used as a pretreatment stage in other processes, in order to protect expensive and/or very sensitive catalysts from specific contaminants. Normally, a large number of distinct chemical reactions occur simultaneously during HDT. However, the relative importance of each HDT reaction is strongly affected by the operating conditions, which defines the process severity.

The oil fractions used as feeds in HDT processes can be very different, ranging from naphtha to heavy

*To whom correspondence should be addressed 
vacuum gasoil (Topsoe et al., 1996). The most common feeds used in Brazilian refineries have a distillation range that is similar to the distillation range of diesel and are known as middle distillates. Middle distillates HDT units of typical Brazilian refineries can be classified into two groups according to process severity: i) HDS units that operate at mild conditions in order to reduce the sulfur content of the products; ii) HDT units that operate at more severe conditions (although relatively mild, when compared to other HDT processes) in order to reduce the sulfur and nitrogen contents of processed feedstocks to very low levels and simultaneously improve the diesel ignition through hydrogenation of aromatics.

Under typical HDS conditions, sulfur removal constitutes the main reaction, while HDN reactions play a secondary role. Similarly, saturation of aromatics is minimized. Under both HDS and HDT conditions, cracking reactions are negligible because of the catalysts and operation conditions that are used. This is observed at the plant site, as the distillation ranges of feedstock and hydrotreated products are essentially the same (Gates, 1979; Topsoe et al., 1996). Besides the desired removal of contaminants, the only significant change of the final product properties that can be observed at the plant site is the reduction of the specific gravity of the hydrotreated products. Fortunately, density changes can be monitored in-line and in real time for monitoring and control of the HDT operation.

Therefore, it is surprising to note that the literature does not discuss any sort of inferential procedure for monitoring and control of sulfur and nitrogen contents based on available in-line measurements of density values. Development of such inferential procedures could exert an enormous effect on the operation of HDT plants, as off-line evaluation of sulfur and nitrogen contents in the lab may take as long as a whole week. Besides, catalysts normally used in HDT units present a continuous and slow activity decay, which imposes a continuous drift of the operating temperatures. This means that constant temperature targets cannot be used for control of the final sulfur and nitrogen contents. Additionally, the catalyst deactivation kinetics is usually unknown and the catalyst is subject to poisoning by unmeasured feed contaminants, which means that it is very difficult to define optimum temperature trajectories a priori. Finally, as a result of the current refinery scenario, feedstock selection has become a management (or logistic) issue, not an operational variable. Therefore correlations oriented to guide feedstock selection like the ones developed by Shih et al. (1992), Ho (2003) and Ho and Markley (2004) have limited value for control applications at the plant site. Besides, they assume that off-line laboratory analyses are available, which is not necessarily true because they are expensive and time demanding, characteristics that one wants to avoid at the plant site when controlling the process. Therefore feedstocks may be changed quite often in a real plant, which means that setpoint references have to be adjusted frequently for different processed feeds. Recent discussions about the characteristics of HDT operations and challenges can be found in the literature (Topsoe et al., 1996; Ancheyta-Juárez et al., 1999; Marroquín-Sánchez et al., 2001). For all the reasons presented above, the development of an inferential method that can be used for in-line evaluation of nitrogen and sulfur removal from oil feedstocks in real time will certainly be welcome by those working in the HDT field.

Nowadays, refineries are commonly using on-line Antek analyzers for sulfur measurement (but not nitrogen). Despite this, one should pay attention to some important points. First, on-line Antek analyzers are not available in all refineries. Second, Antek analyzers are subject to operational problems and require frequent maintenance. Third, implementation of the proposed technique is almost costfree, because density measurements are always available at the plant site. Finally, implementation of the proposed technique provides useful redundancy for process monitoring and control.

The main objective of this work is to evaluate whether the reduction of the specific gravity of the product stream of middle distillates HDT units can be correlated with the sulfur and nitrogen removal at typical HDS operation conditions. As discussed, this correlation can constitute a very useful tool for monitoring and control of the HDT process, allowing for fast in-line estimation of the catalyst activity in real time, independently from any other analytical tests or any kinetic behavior of the catalysts. Therefore, it is far beyond the scope of this work to provide detailed mechanistic interpretation of sulfur removal or nitrogen removal reactions. It is shown here that it is indeed possible to obtain inferences about the sulfur and nitrogen contents of the product stream of HDT processes with fair precision from available measurements of the specific gravity.

\section{EXPERIMENTAL}

Experimental data presented in this work were obtained in HDT pilot plants located at the Petrobras Research Center, Rio de Janeiro, Brazil. Pilot plant reactors consist of stainless steel tubes with internal diameter of $2.24 \mathrm{~cm}$ and volume of approximately $250 \mathrm{ml}$. Tests were carried out isothermically, using 
$50 \mathrm{ml}$ of catalyst. Catalyst was diluted in silicon carbide with a volumetric ratio of 1:1. Reactors were placed in the vertical position and the flow feed was placed at the reactor bottom, so that the flow followed the upward direction.

Different catalysts were used in this work (Ni$\mathrm{Mo} / \gamma$-alumina) and contained $(\% \mathrm{w} / \mathrm{w}) 15$ to $25 \%$ $\mathrm{MoO}_{3}, 2$ to $6 \% \mathrm{NiO}$ and 0 to $4 \% \mathrm{P}$. The catalysts were sulfided in the liquid phase, using a hydrotreated feedstock spiked with a sulfiding agent $\left(\mathrm{CS}_{2}\right)$, to reach a sulfur content of $1-2 \%$ by weight. After completion of catalyst sulfiding, it was assumed that the catalyst was in the active form and that the activity evaluation test could be started. (Presentation of additional catalyst characteristics is not possible for proprietary reasons. However, as shown in the following sections, detailed presentation of catalyst properties is unimportant for the purposes of this manuscript, since variable correlations do not seem do depend on the catalyst characteristics).

Each experimental run consisted of three tests at distinct temperatures, while keeping all other process conditions constant. The critical process variables are the total operating pressure, the hydrogen and feed flow rates, and the reactor residence time (represented as the liquid hourly space velocity (LHSV), defined as the ratio between the volumetric feed flow rate and the catalyst volume).

For correct interpretation and use of the results, tests must be performed under very well controlled conditions. Therefore, evaluation of HDT catalysts in pilot plants must obey a long series of quality requirements in order to ensure the reliability of the obtained information. The first quality requirement regards the stability of the operating conditions. Variations outside previously configured acceptable control limits impede the start of the catalyst evaluation stage. The second quality requirement is related to the stability of the catalyst activity. Monitoring of catalyst activity was performed by measuring of the specific gravity $\left(\mathrm{d}_{20 / 4^{\circ} \mathrm{C}}\right)$ of HDT products at defined time intervals, using an Anton Paar DMA40 digital densimeter, with repeatability of $0.0001 \mathrm{~g} / \mathrm{ml}$ and reproducibility of $0.0005 \mathrm{~g} / \mathrm{ml}$, for density values ranging from 0.68 to $0.97 \mathrm{~g} / \mathrm{ml}$. Catalyst activity was considered to be stable when the difference between three consecutive measurements was within the instrument precision. After catalyst stabilization, overall material balances were performed and samples of the feedstock and hydrotreated products were collected for later off-line characterization in laboratories. The third quality criterion is associated with the calculation of the liquid material balance. The difference between overall inlet and outlet flow rates should be smaller than $2 \%$.

Experiments presented here were obtained in two similar HDT units, using similar feedstocks (middle distillates) and the same catalyst mass (but different catalysts). Operating conditions resembled those of real HDS industrial units $\left(\mathrm{P}=6.0 \times 10^{6} \mathrm{~Pa} L H S V=2.2 \mathrm{~h}^{-1}\right.$, flow rates ratio $\mathrm{H}_{2} /$ feed $=600 \mathrm{Nm}^{3} / \mathrm{m}^{3}, \quad 590<\mathrm{T}<660 \mathrm{~K}$ ). Products were characterized in terms of the specific gravity $\left(\mathrm{d}_{20 / 4^{\circ} \mathrm{C}}-\mathrm{ASTM} \mathrm{D}-4052\right)$, the total sulfur content (ASTM D-5354) and the total nitrogen content (ASTM D-4629).

Due to proprietary reasons, the following notation was adopted to present the available experimental data: (A) higher temperature condition; (B) medium temperature condition; (C) lower temperature condition. (As shown below, real temperatures are not used for model formulation and are not necessary). Additionally, the presentation of the results was divided into two groups in accordance with the used catalysts. The first group contains results of 19 tests performed with the reference catalyst, while the second group contains results of 51 tests performed with all other catalysts.

\section{RESULTS AND DISCUSSION}

\section{Feedstock Characterization}

In order to represent the industrial operation, actual industrial feedstocks were used to perform the tests. A straight run heavy diesel from Cabiúnas crude oil was selected. Due to the long period of time required to perform all tests, various feedstock samples were used. In order to characterize the magnitude of the differences of feed properties, a descriptive statistical analysis of feed properties was carried out. Properties defined in equations 1-7 were calculated and results are shown in Table 1.

Table 1: Descriptive analysis of feedstock properties

\begin{tabular}{|l|c|c|c|c|c|c|c|c|c|}
\hline & \multicolumn{3}{|c|}{ All tests } & \multicolumn{3}{c|}{ Last 25 tests } & \multicolumn{3}{c|}{ First 25 tests } \\
\hline & $\mathbf{d}_{\mathbf{2 0} / \mathbf{4}^{\circ} \mathbf{C}}$ & $\begin{array}{c}\mathbf{S} \\
\mathbf{( m g / k g )}\end{array}$ & $\begin{array}{c}\mathbf{N} \\
(\mathbf{m g} / \mathbf{k g})\end{array}$ & $\mathbf{d}_{\mathbf{2 0 / 4}}{ }^{\circ} \mathbf{C}$ & $\begin{array}{c}\mathbf{S} \\
(\mathbf{m g} / \mathbf{k g})\end{array}$ & $\begin{array}{c}\mathbf{N} \\
(\mathbf{m g} / \mathbf{k g})\end{array}$ & $\mathbf{d}_{\mathbf{2 0} / \mathbf{4}^{\circ} \mathbf{C}}$ & $\begin{array}{c}\mathbf{S} \\
(\mathbf{m g} / \mathbf{k g})\end{array}$ & $\begin{array}{c}\mathbf{N} \\
(\mathbf{m g} / \mathbf{k g})\end{array}$ \\
\hline Mean & 0.9049 & 4063 & 1396 & 0.9051 & 4322 & 1392 & 0.9047 & 3869 & 1365 \\
Standard deviation & 0.0003 & 283 & 81 & 0.0002 & 168 & 102 & 0.0003 & 283 & 82 \\
Confidence interval of the & 0.9047 & 3933 & 1360 & 0.9050 & 4256 & 1352 & 0.9046 & 3758 & 1333 \\
mean & 0.9051 & 4193 & 1432 & 0.9052 & 4388 & 1432 & 0.9048 & 3980 & 1398 \\
\hline
\end{tabular}


Mean

$\bar{x}=\frac{\sum \mathrm{xi}}{\mathrm{n}}$

Variance

$\mathrm{S}_{\mathrm{x}}^{2}=\frac{\sum\left(\mathrm{x}_{\mathrm{i}}-\overline{\mathrm{x}}\right)^{2}}{(\mathrm{n}-1)}$

Standard deviation

$\mathrm{S}^{2}=\sqrt{\mathrm{S}_{\mathrm{x}}^{2}}$

Confidence interval of the mean (t-Student, 95\%)

$\bar{X}=\bar{x} \pm 1,96\left(\frac{S}{\sqrt{n}}\right)$

Confidence interval of the measurements (normal distribution, 95\%)

$\overline{\mathrm{P}}=\overline{\mathrm{x}} \pm 1,96 \mathrm{~S}$

Covariance

$\mathrm{S}_{\mathrm{xy}}^{2}=\sum \frac{\left(\mathrm{x}_{\mathrm{i}}-\overline{\mathrm{x}}\right)\left(\mathrm{y}_{\mathrm{i}}-\overline{\mathrm{y}}\right)}{(\mathrm{N}-1)}$

Correlation Coefficient

$\rho_{x y}=\frac{S_{x y}^{2}}{S_{x} S_{y}}$

Results presented in Table 1 indicate the increase of specific gravity and sulfur content values along the tests, since the confidence intervals of the means (with 95\% confidence) could not be considered equivalent. In relation to nitrogen, the analysis indicates that the confidence intervals of the means cannot be regarded as distinct. However, this is due to the large standard deviations of nitrogen and sulfur contents of the feed, which is due to the characterization errors and to normal fluctuation of feedstocks properties. Therefore, it may be concluded that the feedstocks used along the tests were indeed different, reflecting the variations expected in real plant sites.

In order to minimize the importance of feedstock variations and the possible impact of feedstock variations on the development of the correlations pursued in this work, absolute values of feedstock properties were not used for modeling purposes. Differences observed between properties of the feed and of the hydrotreated products are used here for modeling purposes. This is very convenient for development of inferential procedures, as possible feedstock and catalyst variations are automatically taken into consideration when a process change occurs. For instance, the reduction of the extent of the HDT reactions causes the reduction of the observed density variations, regardless of the feedstock and catalyst properties. Therefore, equations 8-10 define the following set of variables:

Specific gravity variation

$\Delta \mathrm{d}=\mathrm{d}_{20 / 4^{\circ} \mathrm{C} \text { feed }}-\mathrm{d}_{20 / 4^{\circ} \mathrm{C} \text { product }}$

Sulfur conversion

$\Delta \mathrm{S}(\%)=\left(\left(\mathrm{S}_{\text {feed }}-\mathrm{S}_{\text {product }}\right) / \mathrm{S}_{\text {feed }}\right) * 100$

Nitrogen conversion

$$
\Delta \mathrm{N}(\%)=\left(\left(\mathrm{N}_{\text {feed }}-\mathrm{N}_{\text {product }}\right) / \mathrm{N}_{\text {feed }}\right) * 100
$$

\section{Experimental Results Obtained with the Reference Catalyst}

Catalyst performances are usually evaluated and compared to the performance of a reference catalyst. Therefore, whenever experimental runs are carried out to evaluate catalysts, an additional run is performed with the reference catalyst. For this reason, 19 runs were carried out with the reference catalyst. These tests can be regarded as replicates, because similar test conditions were employed, although different samples of the industrial feed and of the reference catalyst were used. Therefore, the replicates contain information about the natural variability of the process. Descriptive statistical analysis of the variables of interest is shown in Table 2. Analytical results of the product characterization are reproduced in Figures 1-3.

One can observe in Figures 1-3 that the variables do not show any significant trend during the analyzed period of time, which seems to validate the hypothesis that fluctuations of feed properties can be minimized when differences between feed and product properties are considered. Besides, given the large quantity of available data, distinct $\Delta \mathrm{S}$ and $\Delta \mathrm{N}$ values were obtained for similar values of $\Delta \mathrm{d}$. The analysis of these experimental points can provide estimates for the minimum modeling errors that can be obtained. Maximum model precision can be associated with $\Delta \mathrm{S}$ and $\Delta \mathrm{N}$ fluctuations, which are presented in Table 3. 
Table 2: Descriptive analysis of the variables of interest as obtained with the reference catalyst

\begin{tabular}{|l|c|c|c|c|c|c|c|c|c|}
\hline & \multicolumn{3}{|c|}{ Condition $\mathbf{A}$} & \multicolumn{3}{c|}{ Condition B } & \multicolumn{3}{c|}{ Condition C } \\
\cline { 2 - 10 } & $\Delta \mathbf{d}$ & $\Delta \mathbf{S}$ & $\Delta \mathbf{N}$ & $\Delta \mathbf{d}$ & $\Delta \mathbf{S}$ & $\Delta \mathbf{N}$ & $\Delta \mathbf{d}$ & $\Delta \mathbf{S}$ & $\Delta \mathbf{N}$ \\
\hline Mean & 0.0094 & 94.8 & 44.9 & 0.0078 & 88.1 & 27.0 & 0.0060 & 77.6 & 14.6 \\
Standard Deviation & 0.0004 & 1.8 & 3.5 & 0.0005 & 2.1 & 3.7 & 0.0003 & 3.1 & 2.6 \\
Confidence interval of & 0.0092 & 93.9 & 42.7 & 0.0075 & 87.2 & 25.4 & 0.0059 & 76.0 & 13.1 \\
the mean & 0.0097 & 95.7 & 47.0 & 0.0080 & 89.0 & 28.6 & 0.0061 & 79.1 & 16.0 \\
Confidence interval of & 0.0085 & 90.9 & 35.3 & 0.0067 & 84.0 & 19.8 & 0.0054 & 70.7 & 8.2 \\
measurements & 0.0104 & 98.7 & 54.7 & 0.0088 & 92.2 & 34.1 & 0.0066 & 84.4 & 21.0 \\
\hline
\end{tabular}

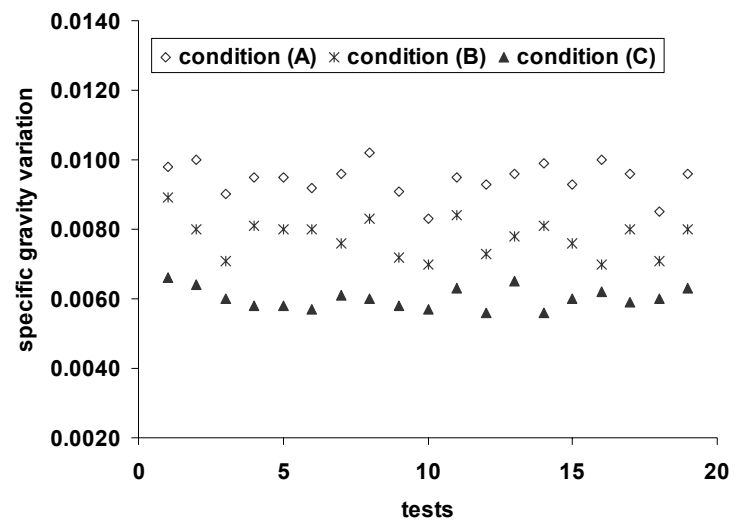

Figure 1: Specific gravity variation in tests performed with the reference catalyst.

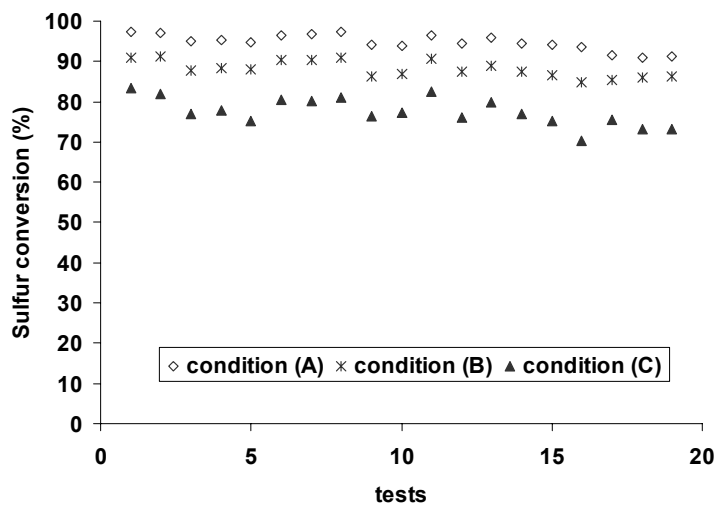

Figure 2: Sulfur conversion in tests performed with the reference catalyst.

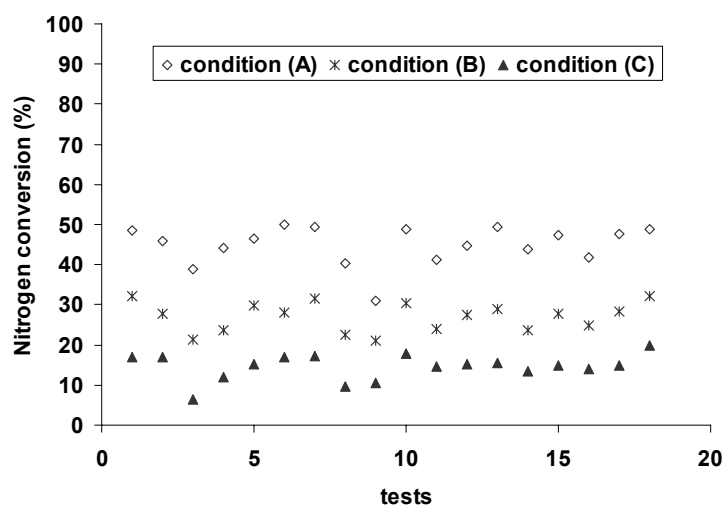

Figure 3: Nitrogen conversion in tests performed with the reference catalyst.

Table 3: Estimates of experimental errors for $\Delta S$ and $\Delta N$ with the reference catalyst

\begin{tabular}{|l|c|c|c|}
\hline & Condition A & Condition B & Condition C \\
\hline$\Delta$ d & 0.0096 & 0.0080 & 0.0060 \\
$\mathrm{~N}^{\text {o } \text { of points }}$ & 4 & 5 & 4 \\
$\Delta$ S Mean & 93.9 & 88.2 & 76.6 \\
$\Delta$ N Mean & 47.1 & 28.5 & 16.1 \\
$\Delta$ S Standard Deviation & 2.9 & 2.5 & 3.4 \\
$\Delta$ N Standard Deviation & 3.6 & 3.9 & 1.8 \\
$\Delta$ S Error & 5.8 & 5.0 & 6.8 \\
$\Delta$ N Error & 7.2 & 7.8 & 3.6 \\
\hline
\end{tabular}


Analysis of the Experimental Results with All Other Catalysts

51 tests were performed with various commercial catalysts and the descriptive statistical analysis of the results is summarized in Table 4. Product characterization is presented in Figures 4-6. As performed previously, fluctuations of $\Delta \mathrm{S}$ and $\Delta \mathrm{N}$ are characterized for different values of $\Delta \mathrm{d}$ and shown in Table 5.

Comparing the results presented in Table 5 with the ones shown in Table 3 for the reference catalyst, it can be seen that the values obtained are very similar in both cases. This seems to indicate that it is not necessary to use any information concerning the catalyst properties for modeling of $\Delta \mathrm{S}$ and $\Delta \mathrm{N}$ as functions of $\Delta \mathrm{d}$. To put this into formal statistical terms, the standard F-test (Himmelblau, 1970; Schwaab and Pinto, 2007) was used to compare the variances obtained in the tests performed with the reference catalyst (19 independent measurements, 18 degrees of freedom) and with the other catalysts (51 independent measurements, 50 degrees of freedom). For the F-distribution, with $95 \%$ confidence, the confidence limits are 0.4 and 2.4, which define the acceptable interval limits for the variance ratio between the two sets, when variances are equal and fluctuations occur at random. In Table 6, it can be seen that all values are within the previously defined interval. Consequently, with $95 \%$ of confidence, variances cannot be considered different. This seems to confirm that there is no need to use any sort of catalyst characterization property to develop the correlation among the data and that all data can be grouped into a single set, as shown in Figures 7 and 8. This may be very important for real plant applications, as catalyst variabilility does not seem to be of fundamental importance for quantitative interpretation of measured data.

Table 4: Descriptive analysis of experimental results with other catalysts

\begin{tabular}{|c|c|c|c|c|c|c|c|c|c|}
\hline & \multicolumn{3}{|c|}{ Condition A } & \multicolumn{3}{|c|}{ Condition B } & \multicolumn{3}{|c|}{ Condition C } \\
\hline & $\Delta d$ & $\Delta \mathbf{S}$ & $\Delta \mathbf{N}$ & $\Delta \mathbf{d}$ & $\Delta \mathbf{S}$ & $\Delta \mathbf{N}$ & $\Delta d$ & $\Delta \mathbf{S}$ & $\Delta \mathbf{N}$ \\
\hline Mean & 0.0088 & 93.0 & 39.7 & 0.0071 & 85.0 & 24.0 & 0.0056 & 73.4 & 13.3 \\
\hline Standard Deviation & 0.0006 & 2.2 & 4.7 & 0.0005 & 3.4 & 3.6 & 0.0006 & 3.6 & 2.8 \\
\hline Confidence interval of the & 0.0086 & 92.4 & 38.2 & 0.0070 & 83.9 & 23.0 & 0.0054 & 72.0 & 12.4 \\
\hline mean & 0.0090 & 93.7 & 41.1 & 0.0073 & 86.1 & 25.1 & 0.0057 & 74.8 & 14.2 \\
\hline Confidence interval of & 0.0076 & 88.3 & 29.3 & 0.0061 & 77.1 & 16.7 & 0.0044 & 63.4 & 6.8 \\
\hline measurements & 0.0100 & 97.8 & 50.1 & 0.0082 & 92.9 & 31.4 & 0.0067 & 83.4 & 19.8 \\
\hline
\end{tabular}

Table 5: Estimates of experimental errors for $\Delta S$ and $\Delta \mathrm{N}$ with other catalysts

\begin{tabular}{|l|r|r|r|r|r|r|}
\hline Condition & \multicolumn{1}{|c|}{ A } & \multicolumn{1}{|c|}{ A } & \multicolumn{1}{|c|}{ B } & \multicolumn{1}{c|}{ B } & \multicolumn{1}{c|}{ C } \\
\hline$\Delta \mathrm{d}$ & 0.0090 & 0.0089 & 0.0074 & 0.0070 & 0.0060 & 0.0056 \\
$\mathrm{~N}^{\text {o } \text { of points }}$ & 4 & 4 & 7 & 5 & 5 & 5 \\
$\Delta \mathrm{S}$ Mean & 91.9 & 92.6 & 87.2 & 80.8 & 74.3 & 73.1 \\
$\Delta$ N Mean & 41.9 & 39.0 & 25.1 & 21.0 & 14.3 & 13.5 \\
$\Delta$ S Standard Deviation & 3.2 & 3.2 & 3.9 & 3.8 & 6.3 & 5.5 \\
$\Delta$ N Standard Deviation & 1.4 & 3.0 & 3.0 & 2.1 & 1.8 & 1.7 \\
$\Delta$ S Error & 6.4 & 6.4 & 7.8 & 7.6 & 12.6 & 11.0 \\
$\Delta$ N Error & 2.8 & 6.0 & 6.0 & 4.2 & 3.6 & 3.4 \\
\hline
\end{tabular}

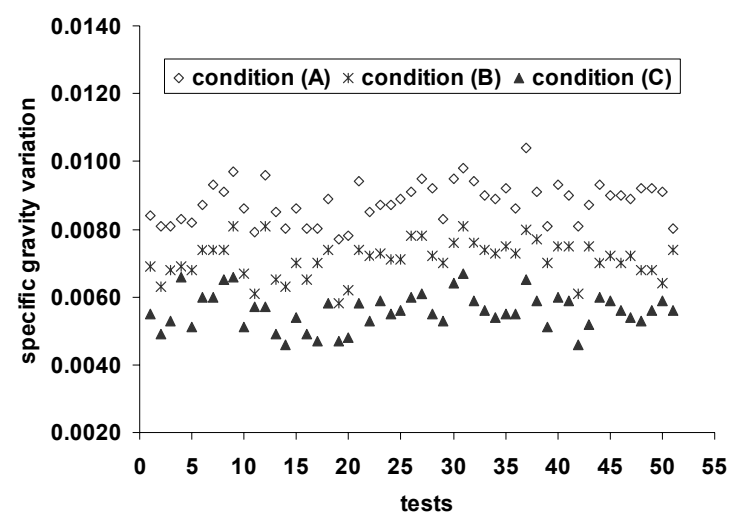

Figure 4: Specific gravity variation in tests performed with all other catalysts.

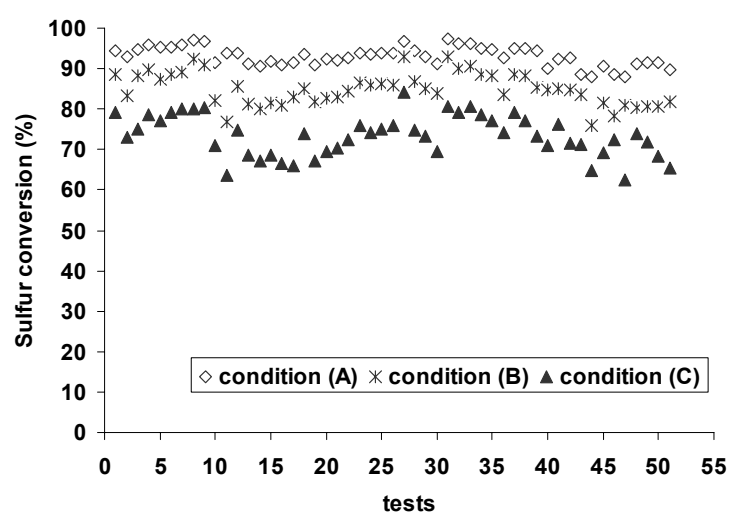

Figure 5: Sulfur conversion in tests performed with all other catalysts. 


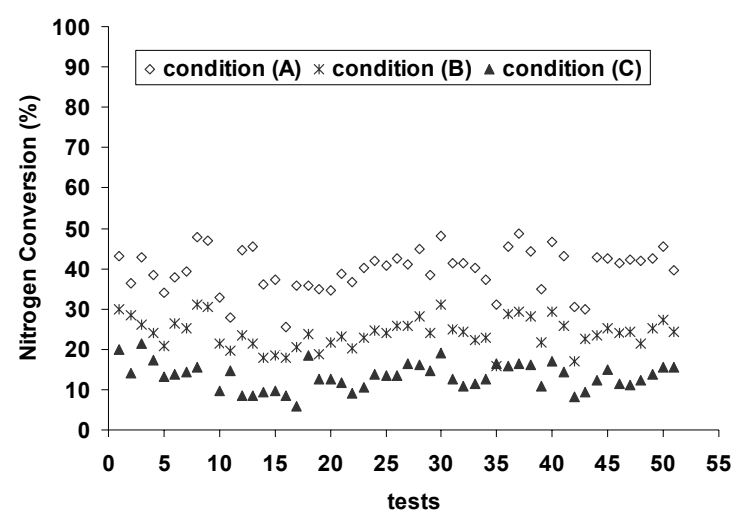

Figure 6: Nitrogen conversion in tests performed with all other catalysts.

Table 6: Results from the application of F-Test

\begin{tabular}{|l|c|c|c|c|c|c|}
\hline \multirow{2}{*}{ Variations } & \multicolumn{3}{|c|}{$\Delta$ S } & \multicolumn{3}{c|}{$\Delta \mathbf{N}$} \\
\cline { 2 - 7 } & Cond. A & Cond. B & Cond. C & Cond. A & Cond. B & Cond. C \\
\hline Standard catalyst & 3.2 & 4.3 & 9.7 & 12.4 & 13.4 & 6.9 \\
Other catalysts & 4.9 & 11.7 & 22.2 & 21.8 & 12.9 & 8.1 \\
Variances Ratio & 0.6 & 0.4 & 0.4 & 0.6 & 1.0 & 0.9 \\
\hline
\end{tabular}

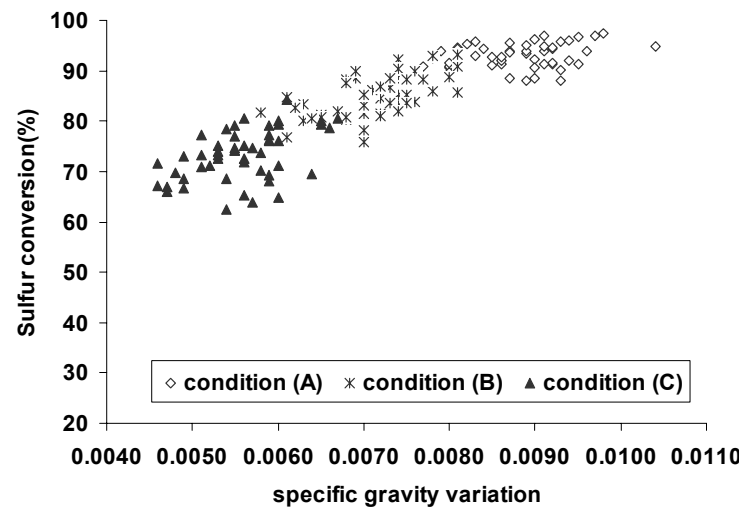

Figure 7: Correlation between specific gravity variation and sulfur conversion.

Correlation coefficients and Figures (7 - 8) show that there are strong linear correlations $\left(\rho_{\mathrm{xy}}=0.9\right)$ between $\Delta \mathrm{d}$ and $\Delta \mathrm{S}$ and between $\Delta \mathrm{d}$ and $\Delta \mathrm{N}$, which means that $\Delta \mathrm{S}$ and $\Delta \mathrm{N}$ are strongly correlated. This also means that $\Delta \mathrm{S}$ and $\Delta \mathrm{N}$ vary simultaneously along the same direction (possibly due to similar kinetic reasons). These results are in accordance with the mechanisms proposed in the literature to explain HDT reactions. Even though there is some controversy in the literature about the nature of the active sites for the HDT reactions, many authors suggest that sulfur and nitrogen reactions occur at the same catalyst sites and follow similar reaction steps,

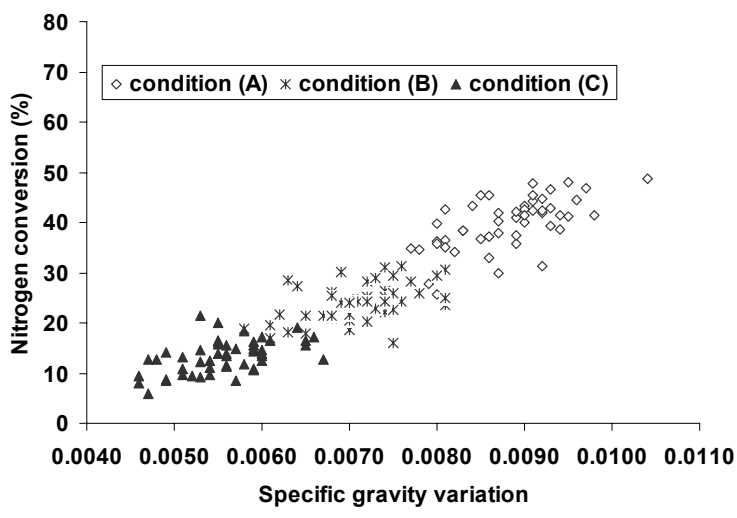

Figure 8: Correlation between specific gravity variation and nitrogen conversion.

although with different reaction rates (Topsoe et al., 1996; Ancheyta-Juárez et al., 1999; MarroquínSánchez et al., 2001). It must be pointed out that the observed correlations do not indicate that density variations are caused only by sulfur and/or nitrogen removal. Observed variations indicate that, although density changes can be caused by different reaction phenomena, they are all correlated and can be represented by a simpler measurement of the extent of reaction during actual HDT operation at usual operation conditions. Therefore, it is clear that the specific gravity variation reflects the progress of the HDT process, and that it can be used to monitor the 
evolution of the process. This result encourages the pursuit of a suitable mathematical model for correlating the experimental data obtained.

\section{MODELING}

\section{Correlation Model}

Riazi and Daubert (1980, 1984) developed correlations to predict the physical properties of oil fractions, such as molecular weight, specific gravity, vaporization heat, carbon-hydrogen ratio and refractive index. Equation 11 presents the general format of the proposed model and equation 12 presents a variation of the general format.

$\theta=\mathrm{a} \theta_{1}^{\mathrm{b}} \theta_{2}^{\mathrm{c}}$

where $\theta_{1}$ and $\theta_{2}$ are properties that represent molecular forces and sizes of the compounds, while $\mathrm{a}, \mathrm{b}$ and $\mathrm{c}$ are model parameters that should be estimated with available data.

$\theta=a \exp \left(b \theta_{1}+c \theta_{2}+d \theta_{1} \theta_{2}\right) \theta_{1}^{e} \theta_{2}^{f}$

where $a, b, c, d$, e and $f$ are model parameters.

It was highlighted that $\theta_{1}$ should depend mostly on the number of carbons, but not on the nature of the hydrocarbon (paraffins, olefins, aromatics or naphthenics). For instance, $\theta_{1}$ might be the molecular weight or viscosity of the compound. On the other hand, $\theta_{2}$ should depend mostly on the nature of the hydrocarbon, such as the specific gravity, the refractive index and the carbon-hydrogen ratio.

It is proposed here that the difference between the specific gravity of the feed and of the product be used as a process characterization factor as defined by equation 13 .

$\theta=a+b \exp \left(c \theta_{1}^{2}+d \theta_{1}\right)$

where $\theta$ represents the nitrogen $(\Delta \mathrm{N} \%)$ or sulfur $(\Delta \mathrm{S} \%)$ conversion and $\theta_{1}$ represents the difference between feed and product specific gravities $(\Delta d)$.

\section{Implementation of the Parameter Estimation Problem}

STATISTICA $^{\mathrm{TM}}$ was used to perform the nonlinear estimation, using the Quasi-Newton method for iterative computations, considering the following aspects:

\section{a) Data Used for Estimation and Model Validation}

Due to the large volume of available data, around $10 \%$ of the experimental points were saved for later use during the model validation stage. Selection of these points was based on the following criteria: a) different $\Delta \mathrm{d}$ values were selected; b) equal numbers of experimental points were selected for each experimental condition; c) the ratio between experimental data obtained with the reference catalyst and with all other catalysts was kept constant and equal to the ratio of the original data set; d) data were selected at random, satisfying the previous criteria.

\section{b) Objective Function Definition}

In order to formulate the parameter estimation problem, the following hypotheses were considered: normally distributed errors, well performed experiments, perfect model, absence of error in the independent variable $(\Delta d)$, independence of different tests and measurements. By applying the Method of Maximum Likelihood (Himmelblau, 1970; Schwaab and Pinto, 2007), the objective function is defined in the form of a weighted least squares function by equation 14

$G=\sum_{i=1}^{N E} \frac{\left(y_{i}-y^{c}\left(x_{i}\right)\right)^{2}}{\sigma_{y_{i}}^{2}}$

where $\mathrm{y}_{\mathrm{i}}$ stands for the experimental data, $\mathrm{y}^{\mathrm{c}}(\mathrm{xi})$ stands for model predictions and $\sigma_{\mathrm{y}_{\mathrm{i}}}^{2}$ represents the variance of measured data.

\section{c) Model Selection}

First, simpler models were evaluated, in order to determine the initial system response. Then, other models were evaluated, with small variations in relation to equation 13, as shown in Table 7. From the point of view of implementation in a real control environment, it must be observed that all proposed models are similar, as they all provide direct and explicit evaluations of sulfur and nitrogen removals from density measurements without any sort of expensive numerical computation. 
Table 7: Evaluation results of the $\Delta \mathrm{N}$ and $\Delta \mathrm{S}$ models

\begin{tabular}{|c|c|c|c|c|c|c|}
\hline \multirow[t]{2}{*}{ Models evaluated } & \multicolumn{2}{|c|}{ G value } & \multicolumn{2}{|c|}{ R Coefficient } & \multicolumn{2}{|c|}{ Residuals Confidence Interval } \\
\hline & $\Delta \mathbf{N}$ & $\Delta \mathbf{S}$ & $\Delta \mathbf{N}$ & $\Delta \mathbf{S}$ & $\Delta \mathbf{N}$ & $\Delta \mathbf{S}$ \\
\hline $1 \mathrm{a}+\mathrm{b} \cdot \Delta \mathrm{d}$ & 241 & 288 & 0.94 & 0.89 & $-7.6 / 8.2$ & $-8.3 / 7.1$ \\
\hline $2 a+b \cdot \Delta d^{2}$ & 218 & 340 & 0.95 & 0.86 & $-7.4 / 8.0$ & $-9.3 / 7.6$ \\
\hline $3 a+b \cdot \exp \left(\Delta d^{2}\right)$ & 218 & 340 & 0.95 & 0.86 & $-7.4 / 8.0$ & $-9.3 / 7.6$ \\
\hline $4 \quad \mathrm{a}+\exp \left(\mathrm{b} . \Delta \mathrm{d}^{2}\right)$ & 521 & 602 & 0.85 & 0.69 & $-10.8 / 13.5$ & $-13.7 / 9.7$ \\
\hline $5 \quad \mathrm{a}+\exp \left(\mathrm{b} \cdot \Delta \mathrm{d}^{2}+\Delta \mathrm{d}\right)$ & 520 & 601 & 0.85 & 0.69 & $-10.8 / 13.5$ & $-13.7 / 9.7$ \\
\hline $6 \mathrm{a}+\mathrm{b} \cdot \exp \left(\mathrm{c} \cdot\left(\Delta \mathrm{d}^{2}\right)+\mathrm{d} \cdot \Delta \mathrm{d}\right)$ & 211 & 226 & 0.95 & 0.91 & $-7.3 / 7.8$ & $-7.3 / 6.6$ \\
\hline $7 \quad \mathrm{a}+\exp \left(\mathrm{c} . \Delta \mathrm{d}^{2}+\mathrm{d} . \Delta \mathrm{d}\right)$ & 215 & 227 & 0.95 & 0.91 & $-7.3 / 7.9$ & $-7.2 / 6.6$ \\
\hline $8 \quad a+\exp \left(c .\left(\Delta d^{2}+\Delta d\right)\right)$ & 278 & 440 & 0.93 & 0.80 & $-8.3 / 9.5$ & $-11.1 / 8.5$ \\
\hline $9 \quad \mathrm{a}+\exp \left(\mathrm{c} .\left(\Delta \mathrm{d}^{2}-\Delta \mathrm{d}\right)\right)$ & 275 & 437 & 0.93 & 0.81 & $-8.2 / 9.4$ & $-13.8 / 8.4$ \\
\hline
\end{tabular}

\section{PARAMETER ESTIMATION RESULTS}

\section{Model Definition}

In order to select the best model, different performance indices were evaluated, as follows:

\section{a) Objective Function (G) Value}

G follows a standard $\chi^{2}$ distribution. Therefore, depending on the number of model parameters and the amount of available data, confidence intervals can be easily calculated for $G$. In order to obtain a $95 \%$ confidence interval for $\mathrm{G}$, final $\mathrm{G}$ values must lie between 150 and 230. According to the results shown in Table 7, it can be seen that models 2, 3, 6 and 7 lead to acceptable $G$ values for nitrogen conversion, while only models 6 and 7 can be considered acceptable for sulfur conversion. The remaining models are not able to explain the experimental fluctuations and must not be selected as the best model.

\section{b) Correlation Coefficients}

The correlation coefficient between experiments and predicted data was considered to be an index of the quality of the model fitting. For $\Delta \mathrm{N}$ estimates, models 2, 3, 6 and 7 led again to the best results. For $\Delta \mathrm{S}$, correlation coefficient values were always lower than the ones obtained for $\Delta \mathrm{N}$, indicating the poorer model performances. Models 6 and 7 were the only ones that led to coefficients above 0.9 , as reported in Table 7.

\section{c) Residuals Analysis}

The distribution of residuals (difference between estimated and experimental data) was also evaluated. It was verified that the residuals distribution showed typical normal behavior. Satisfactory results were obtained for models $1,2,3,6$ and 7 during $\Delta \mathrm{N}$ estimation and with models 6 and 7 during $\Delta S$ analysis. Confidence interval limits were also determined for residuals, by assuming the normal distribution. For $\Delta \mathrm{N}$, confidence limits obtained for models 1, 2, 3, 6 and 7 were very similar, and close to $\pm 8 \%$. For $\Delta \mathrm{S}$, confidence limits were close to $\pm 7 \%$ for models 6 and 7. Comparing these confidence limits with the error estimates previously presented (Tables 3 and 5), one can conclude that the model performances are very reasonable

\section{d) Standard Error of Model Parameter}

Using models 3 and 6 for $\Delta \mathrm{N}$ and model 6 for $\Delta \mathrm{S}$, it was not possible to determine the confidence limits of the parameter estimates, due to ill-conditioning of the Hessian Matrix. This fact is associated with the very large correlation between some of the model parameters and software limitations. In model 6, parameter $b$ is not significant in both cases. By removing this parameter from the expression (giving rise to model 7), the results do not lose quality and the parameter errors can be calculated without problems, which confirms that parameter $b$ is indeed not needed in model 6 .

In accordance with the previous evaluations, model 7 was selected as the best model in both cases. This model, based on Riazi and Daubert's equation after elimination of the parameter $b$, provides good fits for both $\Delta \mathrm{N}$ and $\Delta \mathrm{S}$ and can be used for purposes of monitoring and control in real-time applications.

\section{Evaluation of the Quality of the Estimated Parameters for the Selected Model}

After selecting model 7 as the best model, additional tests were performed in order to evaluate the quality of the model parameters. 


\section{a) Response for Different Initial Guesses}

Estimations were carried out for different initial guesses and the same solution was obtained in all cases. Parameter estimates are shown in Table 8.

\section{b) Evaluation of Parameter Uncertainties}

Errors associated with each model parameter and the respective covariance and correlation matrices of parameter estimates are shown in Tables 8-10. The absolute errors of model parameters were considered to be equal to two times the calculated standard deviations. The relative errors are given as the ratios between the absolute error and the parameter value. One should observe that all parameters are significant within the $95 \%$ confidence limits and that relative errors of the $\Delta \mathrm{S}$ parameters are much lower than those of $\Delta \mathrm{N}$. In both cases, a strong correlation between parameters $\mathrm{c}$ and $\mathrm{d}$ is verified. For this reason, parameters $\mathrm{c}$ and $\mathrm{d}$ were condensed into a single model parameter, leading to models 8 and 9. However, as shown in the previous section, this caused a significant worsening of the estimation quality. Therefore, despite the high observed correlation, parameters $\mathrm{c}$ and $\mathrm{d}$ were kept in the model.

\section{MODEL VALIDATION}

As discussed previously, about $10 \%$ of the initial data was saved for model validation. The descriptive analysis of the residuals is shown in
Table 11 and seems to confirm that the estimates are good, especially for $\Delta \mathrm{S}$. For $\Delta \mathrm{N}$, the obtained confidence intervals were a little higher than the ones obtained previously at the estimation stage. In order to evaluate whether the observed variances were compatible, the F-test (Himmelblau, 1970; Schwaab and Pinto, 2007) was applied between the variances of the residuals obtained at the two stages. The results indicate that the variances cannot be considered to be distinct within the $95 \%$ confidence interval. Therefore, the performance of model 7 is essentially the same for the two experimental data sets, which indicates that model 7 remains valid for the additional experimental data.

Figure 9 clearly shows how useful the developed correlation can be in actual applications. Nitrogen and sulfur removal predictions obtained in real time are compared to laboratory analytical results, which became available two weeks after performing the tests. The results can be regarded as good and indicate the continuous increase of sulfur and nitrogen conversions during the campaign. More important, model predictions and laboratory results cannot be regarded as different within the 95\% confidence limits. This clearly indicates that the proposed strategy can be used for in-line monitoring of sulfur and nitrogen contents during HDT reactions in HDS middle distillates units. However, given the empirical nature of the correlations presented, applications should be limited to the range of density variations observed at the plant site.

Table 8: Parameter error analysis for the selected model 7

\begin{tabular}{|c|c|c|c|c|r|r|r|}
\hline$\Delta \mathbf{N}$ & Value & Absolute error & Relative error & $\Delta \mathbf{S}$ & Value & Absolute error & Relative error \\
\hline $\mathbf{a}_{\Delta \mathbf{N}}$ & -2.2 & 1.5 & 69.0 & $\mathbf{a}_{\Delta \mathbf{S}}$ & 54.0 & 1.3 \\
$\mathbf{c}_{\Delta \mathbf{N}}$ & -21263.0 & 3139.0 & 14.7 & $\mathbf{c}_{\Delta \mathbf{S}}$ & -39058.0 & 1669.0 \\
$\mathbf{d}_{\Delta \mathbf{N}}$ & 607.0 & 30.6 & 5.0 & $\mathbf{d}_{\Delta \mathbf{S}}$ & 761.0 & 15.8 \\
\hline
\end{tabular}

Table 9: Covariance matrices of parameters of the selected model 7

\begin{tabular}{|c|c|c|c|c|c|c|c|}
\hline$\Delta \mathbf{N}$ & $\mathbf{a}_{\Delta \mathbf{N}}$ & $\mathbf{c}_{\Delta \mathbf{N}}$ & $\mathbf{d}_{\Delta \mathbf{N}}$ & $\Delta \mathbf{S}$ & $\mathbf{a}_{\Delta S}$ & $\mathbf{c}_{\Delta S}$ & $\mathbf{d}_{\Delta \mathbf{S}}$ \\
\hline $\mathbf{a}_{\Delta \mathbf{N}}$ & 0.6 & 903.0 & -9.6 & $\mathbf{a}_{\Delta \mathrm{S}}$ & 0.5 & 146.1 & -2.6 \\
\hline $\mathbf{c}_{\Delta \mathbf{N}}$ & 902.6 & 2463483.0 & -23851.0 & $\mathbf{c}_{\Delta \mathrm{S}}$ & 146.1 & 696126.0 & -6346.0 \\
\hline $\mathbf{d}_{\Delta \mathbf{N}}$ & -9.6 & -23851.0 & 235.4 & $\mathbf{d}_{\Delta \mathbf{S}}$ & 2.6 & -6346.0 & 62.2 \\
\hline
\end{tabular}

Table 10: Correlations between parameters of the selected model 7

\begin{tabular}{|c|c|c|c|c|c|c|c|}
\hline$\Delta \mathbf{N}$ & $\mathbf{a}_{\Delta \mathbf{N}}$ & $\mathbf{c}_{\Delta \mathbf{N}}$ & $\mathbf{d}_{\Delta \mathbf{N}}$ & $\Delta \mathbf{S}$ & $\mathbf{a}_{\Delta \mathbf{S}}$ & $\mathbf{d}_{\Delta \mathbf{S}}$ \\
\hline $\mathbf{a}_{\Delta \mathbf{N}}$ & 1.00 & 0.77 & -0.83 & $\mathbf{d}_{\Delta \mathbf{S}}$ & 1.00 & 0.26 \\
$\mathbf{c}_{\Delta \mathbf{N}}$ & 0.77 & 1.00 & -0.99 & $\mathbf{c}_{\Delta \mathbf{S}}$ & 0.26 & 1.00 \\
$\mathbf{d}_{\Delta \mathbf{N}}$ & -0.83 & -0.99 & 1.00 & $\mathbf{d}_{\Delta \mathbf{S}}$ & -0.49 & -0.96 \\
\hline
\end{tabular}


Table 11: Descriptive analysis of residuals obtained in the validation

\begin{tabular}{|l|c|c|}
\hline & $\Delta$ S Residual & $\Delta$ Residual \\
\hline Mean & 0.28 & -0.43 \\
Standard Deviation & 2.5 & 5.3 \\
Maximum Value & 5.5 & 10.6 \\
Minimum Value & -4.5 & -10.1 \\
Confidence interval of the mean & -0.8 & -2.7 \\
& 1.4 & 1.9 \\
Confidence interval of measurements & -4.6 & -10.8 \\
\hline
\end{tabular}

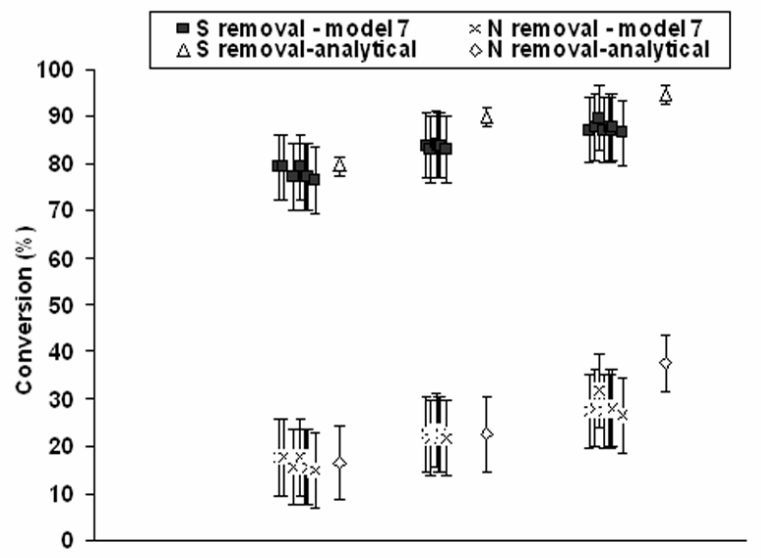

Figure 9: Comparison of calculated conversions using correlation and analytical results.

The experimental data presented here are representative of real industrial HDS middle distillates units. From Tables 2 and 4, one can observe that $\Delta \mathrm{d}$ should be larger than 0.0044 for safe application of the empirical equations, which leads to minimum sulfur removal around $60 \%$ and nitrogen removal around $7 \%$. As usual, the usage of the proposed empirical correlations for extrapolations is not recommended. Despite this, the use of the proposed correlation at the plant site for monitoring and control purposes should be encouraged and reestimation of model parameters should be performed if measured data are found to be outside the recommended experimental region.

\section{CONCLUSIONS}

Results indicate that monitoring of density variations during HDT processes can be used for inline evaluation of catalytic activity in real time. Monitoring of the specific gravity allows for instantaneous estimation of nitrogen and sulfur contents of the hydrotreated products with good precision, allowing for implementation of control procedures in real time.

Analyzing the performances of various commercial $\mathrm{Ni}-\mathrm{Mo} / \gamma$-alumina HDT catalysts, using feedstock and operational conditions that are representative of real industrial units, it was possible to develop a correlation for sulfur and nitrogen conversion as functions of available density measurements. Possible complications arising from usage of different industrial feedstocks and catalysts were eliminated by working with the variations obtained between feedstock and product properties instead of their absolute values.

When experimental results obtained with the reference catalyst were compared to those obtained with all the other catalysts, it was observed that the models shown in equations 1516 can be regarded as the best ones for estimating sulfur and nitrogen conversions in middle distillate HDT reactions.

$$
\begin{aligned}
& \Delta \mathrm{N}(\%)=-2.2+\exp \left(-21263 . \Delta \mathrm{d}^{2}+607 . \Delta \mathrm{d}\right) \\
& \Delta \mathrm{S}(\%)=54+\exp \left(-39058 . \Delta \mathrm{d}^{2}+761 . \Delta \mathrm{d}\right)
\end{aligned}
$$

The proposed inferential scheme allowed for inline evaluation of the sulfur and nitrogen contents of HDT treated oil fractions, for different feedstocks and different catalysts, leading to results that were similar to the ones obtained two weeks afterwards in the lab. 


\section{ACKNOWLEDGMENTS}

The authors thank operators and laboratory staff from Petrobras for providing the experimental data. The authors thank CNPq - Conselho Nacional de Desenvolvimento Científico e Tecnológico - and FAPERJ - Fundação Carlos Chagas Filho de Apoio à Pesquisa do Estado do Rio de Janeiro - for providing scholarships and for supporting this research.

\section{REFERENCES}

Ancheyta-Juárez, J., Aguilar-Rodríguez, E., SalazarSotelo, D., Betancourt-Rivera, G. and LeivaNuncio, M., Hydrotreating of straight run gas oillight cycle oil blends, Appl. Catal. A, 180, 195 1999).

Gates, B., Chemistry of Catalytic Process, McGrawHill, New York (1979).

Himmelblau, D. M., Process Analysis by Statistical Methods, Wiley, New York (1970).

Ho, T. C., Property reactivity correlation for HDS of middle-distillates, Appl. Catal. A, 244, 115 (2003).

Ho, T. C. and Markley, G. E., Property-reactivity correlation for hydrodesulfurization of prehydrotreated distillates, Appl. Catal. A, 267, 245 (2004).

Marroquín-Sánchez, G., Ancheyta-Juárez, J., RamírezZúñiga, A. and Farfán-Torres, E., Effect of crude oil properties on the hydrodesulfurization of middle distillates over NiMo and CoMo Catalysts, Energy Fuels, 15, 1213 (2001).

Riazi, M. R. and Daubert, T. E., Simplify property predictions, Hydrocarbon Process., 59, 115 (2003).

Riazi, M. R. and Daubert, T. E., Characterization parameters for petroleum fractions, Ind. Eng. Chem. Res., 26, 755 (1987).

Schwaab, M. and Pinto, J. C., "Análise de Dados Experimentais I. Fundamentos de Estatística e Estimação de Parâmetros", E-Papers, Rio de Janeiro (2007).

Shih, S. S., Mizrahi, S., Green, L. A. and Sarli, M. S., Deep desulfurization of distillates, Ind. Eng. Chem. Res. 31, 1232 (1992).

Topsoe, H., Clausen, B. S. and Massoth, F. E., Hydrotreating Catalysis, in: J. R. Anderson, M. Boudart (Eds.), Catalysis - Science and Technology 11, Springer Verlag, Berlin (1996). 